\title{
JUSTIÇA COM AS PRÓPRIAS MÃOS: A FIGURA DO JUSTICEIRO NA CPI DESTINADA A INVESTIGAR O EXTERMÍNIO DE CRIANÇAS E ADOLESCENTES
}

\author{
Luisa Rita Cardoso* \\ Universidade do Estado de Santa Catarina - UDESC \\ louisarita@gmail.com
}

\begin{abstract}
RESUMO: A partir de depoimentos prestados à Comissão Parlamentar de Inquérito (CPI) Destinada a Investigar o Extermínio de Crianças e Adolescentes o artigo discute a figura dos justiceiros. A CPI em questão foi instalada no âmbito da Câmara dos Deputados em 1991 em resposta aos altos índices de morte violenta que atingiam crianças e adolescentes pobres no país naquele momento. $\mathrm{O}$ termo justiceiro era então utilizado em referência aqueles que decidiam fazer justiça com as próprias mãos, muitas vezes vitimando um segmento da população infantojuvenil que era visto a partir da lente da marginalidade. Chamados "menores", as representações sociais acerca de tais sujeitos distanciava-os da ideia de infância e juventude que merecia ser protegida, rebaixando o valor de suas vidas. A análise usa o referencial teórico de Giorgio Agamben para pensar tais vidas e mortes a partir da ideia de homo sacer, isto é, da vida que não merece ser vivida e pode, portanto, ser morta.
\end{abstract}

PALAVRAS-CHAVE: Infância - CPI - Extermínio - Justiceiro - Menor

\section{THE LAW INTO THEIR OWN HANDS: JUSTICE- MAKERS IN THE PARLIAMENTARY COMMISSION OF INQUIRY SET TO INVESTIGATE THE EXTERMINATION OF CHILDREN AND ADOLESCENTS}

\begin{abstract}
Testimonials given at the Parliamentary Commission of Inquiry set to investigate the extermination of children and adolescents are taken here as sources to help understand the so-called justice-makers. Such Commission was established in 1991 as an answer to the high number of violent deaths of children and teenagers that were then part of the Brazilian reality. The term justice-maker was used in reference to those who decided to take justice into their own hands by killing those who were socially seen as criminals, even if it meant the death of children and youth population. Their victims were a portion of the population referred to as 'minors' and thus not seen by the same lenses that provided children and adolescents with protection. This analysis uses the work of Giorgio Agamben and his idea of the homo sacer to explain why such lives were seen as lives not worth living and could, therefore, be killed.
\end{abstract}

Doutorada em História pela Linha de Pesquisa: Culturas Políticas e Sociabilidades do Programa de Pós-Graduação em História da Universidade do Estado de Santa Catarina - UDESC. 
KEYWORDS: Childhood - Parliamentary Commission of Inquiry - Extermination - Justice-maker Minor

\section{A CPI}

Em 26 de setembro de 1989, a Folha de S. Paulo trazia na capa, como sua principal notícia, a seguinte afirmação: "Esquadrão da Morte mata um menor a cada 2 dias no país" (ESQUADRÃO, 1989, p. 1). No interior do jornal, a reportagem especificava que o levantamento de dados havia sido feito nos estados de São Paulo, Rio de Janeiro, Espírito Santo, Maranhão, Mato Grosso, Distrito Federal, Pará, Amazonas, Rio Grande do Norte, Alagoas, Paraíba, Piauí, Pernambuco, Rio Grande do Sul e Santa Catarina a partir de registros dos Institutos Médicos Legais (IML) e de arquivos policiais e de jornais. Como resultado dessa pesquisa, realizada em parceria entre o Movimento Nacional de Meninos e Meninas de Rua (MNMMR) e o Instituto Brasileiro de Análises Sociais e Econômicas (Ibase), foi elaborado um dossiê acerca da morte violenta de crianças e adolescentes, que chegou ao total de 624 registros para indivíduos entre 0 e 18 anos, no período de janeiro de 1988 a julho de 1989. Com a divulgação de tais dados às autoridades e políticos, o MNMMR pretendia que a Polícia Federal investigasse a atuação de esquadrões da morte e que, no âmbito do poder legislativo federal, fosse criada uma Comissão Parlamentar de Inquérito (CPI).

Alguns dias depois, em edição do dia 29 de setembro, uma reportagem da mesma Folha afirmava: "Senador quer CPI para crimes contra menores" (DIMESTEIN, 1989, p.4). O parlamentar em questão era Fernando Henrique Cardoso (PSDB), senador pelo estado de São Paulo entre 1989 e 1994, que teria manifestado a intenção de criar uma CPI para abordar o tema do extermínio. De acordo com a reportagem, FHC já teria feito contato com líderes do PMDB, PT, PTB e PRB, dos quais havia recebido apoio, e pretendia, com a Comissão, convocar para depor entidades ligadas ao campo da infância bem como autoridades policiais. O senador, no entanto, não levou a ideia adiante, visto que não há qualquer registro no Diário do Congresso Nacional de que o tema tenha sido abordado por ele em plenário. ${ }^{1}$

\footnotetext{
Foi feita pesquisa com as entradas "Fernando Henrique Cardoso", "CPI", "crianças" e "menores" no período entre 26 de setembro de 1989, data em que o dossiê do MNMMR foi abordado na Folha de S. Paulo, e 24 de abril de 1990, quando a deputada Benedita da Silva tratou do tema no Plenário da Câmara dos Deputados pela primeira vez. Além disso, o site do Senado Federal mantém registro dos
} 
Iniciava-se então um processo para que o poder legislativo federal assumisse a iniciativa de investigar os altos índices de violência contra as população infantojuvenil nos grandes centros urbanos brasileiros. Apesar da intenção do senador Fernando Henrique Cardoso, foi na Câmara dos Deputados que uma Comissão Parlamentar de Inquérito foi criada com o intuito de investigar tal problema, a saber, a CPI Destinada a Investigar o Extermínio de Crianças e Adolescentes. É sobre essa que esse artigo se debruça com o intuito de compreender a ação dos chamados "justiceiros", atores importantes no contexto da violência contra a população infantojuvenil pobre no Brasil do final da década de 1980 e início dos anos 1990. Não à toa a CPI adotou o termo "extermínio", que era compreendido como a morte sistemática e violenta de crianças e jovens pobres nas grandes cidades brasileiras. Em seu relatório, indica 4.611 mortes por homicídio de menores de 17 anos no período de 1988 a 1990 e o assassinato diário de pelo menos dois jovens em São Paulo. ${ }^{2}$ (CPI, 1992, p. 3)

O processo de instalação da referida Comissão teve início em 24 de abril de 1990, durante a $48^{\mathrm{a}}$ legislatura da Câmara dos Deputados, quando a parlamentar Benedita da Silva (PT-RJ) discursou no Plenário da Câmara sobre a situação da criança e do adolescente pobres no país e comunicou que daria entrada em requerimento solicitando a criação de CPI para abordar o problema (DIÁRIO DA CÂMERA DOS DEPUTADOS, 1990, p. 3393). Na ocasião, o deputado Elias Murad (PSDB-MG) apoiou a fala da parlamentar e parabenizou-a pela iniciativa, ressaltando o problema do uso de entorpecentes, sobretudo de substâncias voláteis, como uma questão de saúde da população infantojuvenil que precisava ser levada a sério.

Quase dez meses depois de levantar no Plenário da Câmara dos Deputados a ideia da CPI, em 21 de fevereiro de 1991, já durante a 49ª legislatura da Câmara dos Deputados, a deputada Benedita da Silva (PT-RJ) trouxe o assunto à tona novamente:

Nestes dez meses tenho pedido, falado, quase implorado às Lideranças que se instale uma Comissão Parlamentar de Inquérito, embora não nos interesse uma comissão que se esgote entre quatro paredes. Queremos que ela seja um subsídio para que as autoridades

pronunciamentos feitos por parlamentares e não consta, nos anos de 1989 e 1990, que Fernando Henrique Cardoso tenha abordado o tema da violência contra crianças e adolescentes em nenhum sentido. Disponível em: < https://www25.senado.leg.br/web/atividade/pronunciamentos//p/parlamentar/1634/1989> e $>$ https://www25.senado.leg.br/web/atividade/pronunciamentos//p/parlamentar/1634/1990 $>$. Acesso em 10 de janeiro de 2019. 
competentes possam fazer valer nossos princípios constitucionais que dão garantia à criança e ao adolescente. (DIÁRIO DA CÂMARA DOS DEPUTADOS, 1991, pp. 519-520)

A deputada referia-se a um requerimento encaminhado por ela em 10 de maio do ano anterior para que se criasse a Comissão Parlamentar de Inquérito para investigar o extermínio de crianças e adolescentes no Brasil (DIÁRIO DA CÂMARA DOS DEPUTADOS, 1990, p. 4568), o qual não obteve o número de assinaturas necessárias para que fosse efetivado. Após sua fala, seguiram-se a dos deputados Edson Silva (PDT-CE), Aldo Rebelo (PCdoB-SP), e Irma Passoni (PT-SP), do mesmo partido da requerente, todas em apoio à criação de uma Comissão para tal fim. Alguns dias depois, em 27 de fevereiro, a deputada encaminhou requerimento solicitando o desarquivamento da proposta de criação de CPI para investigar esses crimes (DIÁRIO DA CÂMARA DOS DEPUTADOS, 1991, p. 881). Finalmente, em 04 de maio daquele ano, a Comissão foi instalada.

Faz-se necessário lembrar que desde fevereiro de 1989 estava em pauta no Congresso a criação do ECA, que visava substituir o Código de Menores de 1979, criando um novo paradigma para o campo dos direitos da criança e do adolescente no Brasil. Para tanto, foi criada a Comissão Especial Criança e Adolescente, da qual a deputada Benedita da Silva foi membro titular, incumbida de debater e formular a proposta de legislação que seria votada pelo Plenário. Em 28 de junho de 1990, foi aprovado pela Câmara dos Deputados e, em 13 de julho do mesmo ano, sancionada pelo presidente como Lei no 8.069 .

Com o objetivo de indicar os responsáveis pelas ações de extermínio e, a partir da compreensão do problema encaminhar políticas públicas no sentido de superá-lo, a CPI realizou atividades que reuniram 114 depoimentos de crianças e jovens em situação de rua, familiares de vítimas, deputados, autoridades do Poder Judiciário, representantes da sociedade civil organizada e das polícias civil e militar. Para além, ouviu Agop Kayayan, representante do Fundo das Nações Unidas para a Infância (UNICEF), Renato Aragão e Roger Moore, embaixadores da mesma organização; governadores dos estados de Pernambuco, Paraíba, Espírito Santo, Bahia e Rio de Janeiro; o vice-governador do estado de São Paulo; o prefeito de Salvador, Fernando José; e a prefeita da cidade de São Paulo, Luiza Erundina. Todo o material recolhido ao longo dos nove meses de 
trabalho da Comissão foi sistematizado pela relatora deputada Fátima Pelaes (PFL-AP), dando origem a um extenso documento aqui tomado como fonte documental.

\section{INFÂNCIA E POBREZA}

A preocupação com a infância e a juventude no Brasil tem, historicamente, um recorte de classe: são as crianças pobres que preocupam o Estado, por suas condições materiais serem entendidas como propícias à marginalidade. Inserido nos estudos de História da Infância e Juventude, o historiador britânico Hugh Cunningham sugere o uso de duas categorias para abordar a questão de classe nesse grupo social, a saber: children of the wealthy (crianças dos ricos) e children of the poor (crianças dos pobres), sendo estas compreendidas como as que, de alguma forma, contribuem para a renda de sua família; e aquelas como as que, ao contrário, geram despesas para seu núcleo familiar na infância e até mesmo posteriormente (CUNNINGHAM, 1998, p.11951208). Compreendo que as crianças e jovens a que este estudo se dedica são as crianças dos pobres, visto que foi na rua, quando buscavam ganhar a vida - para ajudar na renda familiar ou, no caso daqueles/as em situação de rua, como única forma de sustento que foram atingidos/as pela violência.

A noção de pobreza é aqui compreendida como situações de carência em que indivíduos não conseguem manter o mínimo necessário para a satisfação das necessidades mais básicas em determinado contexto social e histórico em que estão inseridos. Entende-se, portanto, a pobreza como variável social inscrita em uma determinada temporalidade. A fim de medir a pobreza é necessário estabelecer uma medida invariante, e esta é a chamada linha de pobreza, que é o "parâmetro que permite a uma sociedade específica considerar como pobres todos aqueles indivíduos que se encontrem abaixo do seu valor" (BARROS; HENRIQUES; MENDONÇA, 2000, p. 124). O atendimento às necessidades básicas refere-se à possibilidade de arcar com os custos de alimentação, habitação, transporte, saúde, lazer e educação, sendo considerados pobres os indivíduos com renda familiar per capita inferior ao valor necessário para arcar com tais custos. Outro indicador a ser considerado aqui é o da linha da indigência, que se refere a indivíduos com renda familiar per capita insuficiente para atender às necessidades relativas à alimentação. (ROCHA, 2006) 
Chamados de "a década perdida" 3 , os anos de 1980 e o início da década de 1990 foram marcantes para a vida econômica do Brasil. O aumento do preço do barril de petróleo em 1979 - chamado de o segundo choque do petróleo -, combinado com os problemas acarretados pelo fim do chamado "milagre brasileiro" e do primeiro choque do petróleo, de 1973, levou o país a conhecer, pela primeira vez, a inflação anual de três dígitos em 1980 (SINGER, 2001). Desenvolveu-se uma crise inflacionária de grandes proporções, que, a partir de 1982, agravada pelo desemprego em massa, causado pelas demissões feitas pela indústria e grandes empresas no cenário de recessão. Enquanto produção, emprego, massa salarial e consumo caíam, o custo de vida aumentava. Foram as camadas populares as mais atingidas pela crise econômica, e o número de pobres no país aumentou significativamente: em 1986 havia 37,6 milhões de pobres e 13,1 milhões de indigentes; número que saltou para 63,1 milhões de pobres e 30,8 milhões de indigentes no ano de 1990. (BARROS, 2000)

Não é o intuito aqui estabelecer uma relação causal entre pobreza e violência, o que seria alimentar a falsa percepção de que "todo pobre é violento". Nesse sentido, apoio-me nos estudos de Paulo Sérgio Pinheiro, para quem os ambientes social, cultural e familiar dos mais empobrecidos e marginalizados cria condições para o maior grau de envolvimento dessa população em crimes e conflitos violentos, mas também faz com que recaia sobre esses maior grau de repressão e aplicação de sanções penais do que sobre os mais abastados, que tem maior impunidade face aos crimes que cometem (PINHEIRO, 1998). As crianças e adolescentes vítimas dessa violência eram majoritariamente meninos e meninas que viviam ou andavam pelas ruas das grandes cidades do país.

Chamados meninos e meninas de rua, esses sujeitos não eram necessariamente desprovidos/as de vínculo familiar, o que o estigma construído sobre os mesmos ao longo dos anos leva a maior parte da população a acreditar. Além daqueles/as que de fato moravam nas ruas das grandes cidades, eram crianças e jovens que passavam o dia fora de casa em busca de meios - nem sempre lícitos - para contribuir com o sustento da família. Também a busca por diversão com outras crianças e jovens era motivo que levava muitos/as às ruas, pois essas eram “também um espaço vivencial significativo

3 A expressão "década perdida" é utilizada em referência à crise econômica que assolou o país nos anos 1980. Debate-se, no entanto, que do ponto de vista da democracia esse foi um período de ganhos expressivos para o Brasil. VER: MALLMANN, 2008. 
para projeção de atitudes e comportamentos que alimentavam a vida de um senso lúdico peculiar, no qual a aventura, a brincadeira e a marotagem eram valorizadas como realizações de fantasias infantis" (FRONTANA, 1999, p. 121). Independentemente da manutenção de laços familiares ou de terem residência fixa, no entanto, esses meninos e meninas que exerciam estratégias de sobrevivência nas ruas eram socialmente vistos de uma única forma: perigosos/as.

A situação de pobreza dessas crianças e adolescentes fazia com que fossem lidos como ameaça social, o que os tornava "alvos preferenciais de grupos de extermínio constituídos, nos bairros que compõem a chamada periferia das regiões metropolitanas, para execução sumária de suspeitos e aqueles estigmatizados como potenciais perturbadores da ordem local" (PERES, 2006 p. 31). Ocupando a rua permanentemente - como moradores - ou revezando entre essa e a casa de familiares, essas crianças e adolescentes tinham aí um espaço de sobrevivência considerado inadequado, fora do lugar na perspectiva da infância burguesa.

\section{OS "MENORES"}

A defesa da ordem não raro vinha acompanhada dal defesa da propriedade. Com o objetivo de promover a proteção do patrimônio, criava-se uma hierarquização do valor da vida, que diminuía a de crianças e adolescentes pobres e dava a esses um outro status: tornavam-se menores. É ilustrativo disso o caso do presidente da Associação Comercial da Duque de Caxias, Getúlio Gonçalves, que foi convocado a depor devido à suspeita de que a associação de classe por ele presidida tinha ligação a empresas de segurança privada acusadas de extermínio. Em seu depoimento, em 08 de agosto de 1991, o termo utilizado pelo senhor Gonçalves é "menor". Parece tão difícil enxergar o "menor" como criança e/ou adolescente que o depoente refere-se quatro vezes ao ECA como "Estatuto do Menor e do Adolescente." (CPI, 1992, pp. 78-82)

Há uma produção discursiva em torno desses sujeitos assim chamados. Presente na legislação brasileira desde o primeiro Código Criminal, de 1830, o sentido atribuído ao termo pelo Império era aquele do menor de idade, a quem não seriam imputadas as mesmas penas que aos adultos. Quase um século depois, em 1927, instituiu-se o Código de Menores, "que motivou a criação, nas capitais de diversos estados do Brasil, dos chamados Juizados de Menores" (AREND, 2011), cujo objetivo 
era lidar com os problemas de crianças e jovens tidos como desamparados e delinquentes. Durante o Estado Novo (1937-1945), duas categorias foram estabelecidas no âmbito institucional de políticas voltadas à infância, a saber: o 'menor' e a 'criança'. A fim de compreender quem são esses sujeitos denominados menores, é válido observar que no Decreto-lei n 3.799 de 5 de novembro de 1941, que criou o Serviço de Atendimento ao Menor (SAM), o termo utilizado é "menores desvalidos e delinquentes."4 Era esse o grupo social a que a nova instituição, de caráter nacional, dedicar-se-ia a fim de promover assistência, internamento, abrigo, educação, instrução e tratamento somato-psíquico. Consolidava-se, assim, a figura do menor como uma pessoa pobre. $^{5}$

Giorgio Agamben (2002), pensador italiano da área da Filosofia do Direito, recupera nos gregos da Antiguidade dois temos que correspondem a diferentes tipos de vida. O primeiro deles é zoé, a vida natural (ou vida nua), o outro, bíos, a vida qualificada. $\mathrm{O}$ autor busca no pensamento de Aristóteles a referência ao bíos politicós, que correspondia à vida política no pensamento do filósofo. A distinção entre os dois termos fica mais explícita quando tomamos o sentido atribuído na Grécia Antiga. Para os gregos, afirma Agamben, a ideia de zoé politiké era impensável, pois a zoé era a mera condição de vivente, e estava associada a "mera vida reprodutiva". Era a bíos, como vida atrelada às ações do sujeito, que os gregos atribuíam valor. Para o autor, o paradigma da modernidade está fundado sobre a politização da zoé, ou seja, a inserção da vida nua no campo do político - configurando o que Michel Foucault chamou de biopolítica - e, para além, a progressiva coincidência do espaço da vida nua com o espaço político, chegando à possibilidade de indistinção entre vida nua e vida qualificada.

Uma outra figura trazida, dessa vez do direito romano, para o debate do pensador italiano é a do homo sacer, cuja vida era simultaneamente matável e insacrificável, no sentido de que matá-lo não seria objeto de punição, mas sua vida, sacra, não poderia ser sacrificada. A vida do homo sacer estaria, para Agamben, tanto

\footnotetext{
4 Decreto-lei $\mathrm{n}^{\mathrm{o}} 3.799$ de 5 de novembro de 1941. Disponível em: <http://www2.camara.leg.br/legin/fed/declei/1940-1949/decreto-lei-3799-5-novembro-1941-413971publicacaooriginal-1-pe.html>. Acesso em 30 de julho de 2018.

5 É importante destacar que o termo menor, quando por mim utilizado, refere-se ao termo jurídico que remete à menoridade, não sendo o intuito corroborar com o estigma que o mesmo carrega.
} 
fora do direito humano quanto do divino. Para o autor, o homo sacer é aquele cuja única vida é a zoé, "uma obscura figura do direito romano arcaico, na qual a vida humana é incluída no ordenamento unicamente sob a forma de sua exclusão (ou seja, de sua absoluta matabilidade).” (AGAMBEN, 2002, p. 16)

Agamben utiliza uma outra noção para articular seu argumento, a de "vida indigna de ser vivida". Tal conceito foi elaborado por Karl Binding, jurista, e Alfred Hoche, professor de Medicina, e aparece num texto de 1920 cujo objetivo era discutir ética e juridicamente a eutanásia. A expressão, para o filósofo, é de grande importância porque procurava estabelecer uma nova categoria jurídica, que "corresponde ponto por ponto, ainda que em uma direção pelo menos aparentemente diversa, à vida nua do homo sacer" (AGAMBEN, 2002, p. 146). Os autores do manifesto pelo direito à eutanásia, no entanto, não podiam saber que a ideia de que certas vidas não merecem ser vividas justificaria atrocidades tal como os campos de concentração, onde os/as prisioneiros/as eram desprovidos/as de qualquer bíos e seus algozes detinham o poder de estabelecer quando suas vidas poderiam deixar de ser vividas.

Assim, para Agamben, é a partir do estabelecimento de quais vidas não são dignas de serem vividas que a "vida cessa de ter valor jurídico e pode, portanto, ser morta sem que se cometa homicídio" (AGAMBEN, 2002, p. 146). Os menores no Brasil eram aqueles cujas vidas não eram socialmente vistas como válidas e, eram, nesse sentido, vidas nuas. Vistos como ameaça social, são despidos de bíos e de tudo aquilo que diz respeito ao campo do político. Crianças e adolescentes brancos das camadas médias eram vistos como sujeitos de direitos, dignos de serem amados, cuidados e protegidos. A vida do menor, no entanto, não tinha o mesmo valor. O trecho a seguir é ilustrativo dessa percepção:

O SR. GETÚLIO GONÇALVES - A vida da comunidade fluminense tem muito valor desde que vivida com critério, com dignidade, alguém que participe do lado positivo da vida, da formação de um município e do seu crescimento, acho que tem um valor incomensurável. Agora quem se propõe a viver no crime e na marginalidade, consequentemente, ele mesmo, deve dar pouco valor à vida (...).

O SR. DEPUTADO CÉLIO DE CASTRO - Quer dizer que a marginalidade implica num valor de vida diferente do cidadão comum?

O SR. GETÚLIO GONÇALVES - Que alguém se propõe na vida. Acho que a pessoa que tem um trabalho, que vive com dignidade, que 
chefia uma família, esse dá um valor muito maior à vida. Não sou eu quem estou diminuindo o valor daquele que vive na marginalidade. Quem diminui o valor de quem vive na marginalidade é o marginal (...).

O SR. DEPUTADO CÉLIO DE CASTRO - Sr. Getúlio, V. Sa não acha que essa sua colocação de diferenciar a vida de um infrator de uma pessoa não infratora propicia uma base de sustentação, vamos dizer assim, teórica, para justificar o extermínio? (CPI, 1992, p. 80)

A pergunta final do deputado Célio de Castro é pertinente, ao que o interpelado respondeu negativamente. Getúlio Gonçalves parece sintetizar o pensamento do filósofo italiano, que à época sequer havia publicado suas reflexões acerca do homo sacer. ${ }^{6}$ Ao tentar justificar sua colocação, utiliza-se de sua trajetória pessoal, dizendo procurar viver em retidão para que sua vida não ficasse exposta ao preço que aqueles a quem chama de marginais pagavam, ou seja, a morte. Para ele, o indivíduo envolvido em atividades criminais desvalorizava a própria vida porque a expunha aos perigos do mundo do crime, mas reafirma não ser ele a julgar o valor da vida. A pergunta feita pelo deputado Célio de Castro na sequência é sobre seu posicionamento em relação à pena de morte:

O SR. GETÚLIO GONÇALVES - Olha, tenho formação católica, fui criado em colégio de irmãs, meus filhos estudam em colégio de irmãs e de padres, mas com essa violência atual chegando ao ponto que chega é de parar para pensar, para saber se a gente continua com as mesmas conviç̧ões religiosas, dada a violência que sofremos. Há seqüestros intermináveis, violências etc. Nem sei se nesses casos específicos desse até para torcer um pouco e pensar até que seria um geito (sic) até de dar um basta em tanta violência, em tanto descontrole em conseqüência de uma vida que a gente sabe que cada dia fica mais difícil. É para se parar para pensar. Não tenho essa convicção, mas temos que parar para pensar. O meu ponto de vista é este. (CPI, 1992, p. 80)

Apesar do recurso discursivo feito à sua formação cristã, talvez na tentativa de se estabelecer perante a audiência como alguém de valores positivos de fraternidade e defesa da vida, Getúlio Gonçalves não se declara contrário à pena de morte. Não é a intenção aqui dar conta do debate ético acerca da pena de morte, mas uma reflexão

\footnotetext{
6 A obra Homo sacer. Il potere sovrano e la nuda vita é publicada pela primeira vez em 1995.
} 
Disponível em: www.revistafenix.pro.br

parece necessária: em que medida a aplicação desta se aproxima da decisão acerca de quais vidas merecem ser vividas?

A psicóloga Nancy Cardia (1995), no decorrer da década de 1990, realizou diversos estudos acerca da representação da violência na sociedade brasileira. Um deles foi realizado entre 1989 e 1991 em parceria com a Comissão de Justiça e Paz - órgão de defesa dos direitos humanos ligado à Igreja Católica Apostólica Romana -, em São Paulo e resultou no livro Direitos humanos: ausência de cidadania e exclusão moral. A partir dos dados coletados, Cardia concluiu que há uma exclusão moral na sociedade brasileira, ou seja, que para determinados grupos a injustiça estaria legitimada, posto que, por serem considerados inferiores, estão excluídos da noção de humanidade. Atos considerados injustos para aqueles cujas vidas são dignas de serem vividas não geram culpa-se cometidos contra o homo sacer, e encontram sua legitimidade na "crença arraigada (e devidamente estimulada pelos interessados na exclusão) naqueles mitos sociais: a inferioridade social e racial, a eventual 'ameaça' de certos grupos sociais, o julgamento moral sobre o comportamento dos que são 'subhumanos' ou, no limite, ‘animais'. É só a partir dessa visão de mundo que se pode compreender a atuação de justiceiros e de grupos de extermínio.

\section{OS JUSTICEIROS}

Dados da Pesquisa Nacional por Amostra de Domicílios (PNAD) de 1988 indicaram que $72 \%$ dos/as brasileiros/as envolvidos/as em conflitos criminais não usavam o sistema judicial para solucionar seu problema, o que é indicador tanto do descrédito quanto das limitações de acesso ao mesmo. Combinados com a pouca confiança também na instituição policial, esses elementos levavam cidadãos/as a duas atitudes: uns se rendiam ao sentimento de vulnerabilidade, outros, procuravam alternativas para resolver seus problemas. Decorre da última o fenômeno da privatização da justiça e da segurança, que, via de regra, se dava para além dos limites da legalidade. Duas alternativas se apresentariam: a primeira se resume à ideia de "fazer justiça com as próprias mãos"; a outra, no apoio ao uso da força letal contra supostos criminosos. (CALDEIRA, 1999)

Nesse sentido, os justiceiros são aqueles que veem a si mesmos como paladinos da segurança e da justiça e recebem, de setores da comunidade em que atuam, 
apoio para agir letalmente. Esse suporte se daria por verem na figura do justiceiro alguém que oferece proteção mas, para além dessa aceitação, também o medo e o silêncio são parte de um pacto estabelecido entre ele e a comunidade. Normalmente moradores das periferias ou favelas em que atuavam, esses exterminadores - que agiam sozinhos ou em grupos - eram também parte da população de baixa renda que vitimavam (CASTRO, 1993). A CPI deixou explicitada a sua interpretação do problema:

A violência praticada pelos chamados "justiceiros" infelizmente não tem se alimentado só de omissões governamentais: expressiva parcela da população apoia e legitima ações dessa natureza, motivada pela insegurança diária. Esta CPI tem verificado que setores da sociedade têm aproveitado dessa sensação generalizada de medo social para incitar a prática de justiça pelas próprias mãos.O exemplo do programa da Rádio Tupy ilustra bem o que queremos aqui evidenciar. (CPI, 1992, p. 7)

O programa de rádio mencionado é o Patrulha da Cidade, transmitido pela Super Rádio Tupi, do estado do Rio de Janeiro ${ }^{7}$, então sob o comando de Samuel Corrêa, o Samuca, eleito deputado estadual pelo Partido da Mobilização Nacional em 1990. O slogan "prá quem tem fraco por programa forte" remete ao conteúdo policial veiculado. No caso em questão, após uma crítica à falta de atuação da polícia no combate ao crime, foi feita uma apologia ao justiçamento e à execução daqueles considerados criminosos. ${ }^{8}$ Além da já mencionada atuação dos meios de comunicação para a propagação de representações sociais sobre crianças e adolescentes pobres como perigosos, vê-se que também havia a incitação à violência e ao papel desempenhado por justiceiros. Na reunião do dia 13 de agosto de 1991, a presidente da Comissão, deputada Rita Camata, comunicou o encaminhamento de ofício ao Procurador-Geral de Justiça do Rio de Janeiro junto de fitas contendo 20 horas de gravações do programa de rádio,

7 O programa de rádio Patrulha da Cidade existe há 57 anos e, atualmente, é apresentado por Mario Belisário.

8 O trecho transcrito no relatório final da CPI é o seguinte: Atenção "coveiro", enquanto o Comandante do $20^{\circ}$ Batalhão não toma uma providência "vamos vê" se a gente "derruba" uma porção de vagabundo, porque lugar de pilantra, safado, traficante, que inferniza famílias, é embaixo da terra, comendo capim pela raiz. Tem mais é que morrer!... Porque bandido que o caçador não trata bem, mata mesmo, "na melhor", é traficante safado" (trecho retirado de fitas com a gravação do programa enviados pela emissora a pedido desta CPI). 
visto que, no entendimento da CPI, alguns dos textos incitavam contra a paz pública. (CPI, 1992, p. 98)

A socióloga Martha Huggins (2005) buscou compreender melhor as relações que explicariam o aumento da violência contra crianças e adolescentes no Brasil da redemocratização e apurou quatro principais elementos, que nesse estudo sintetizo em duas motivações: motivos relacionados à justiça e motivos econômicos. Quanto aos motivos relacionados à justiça, além da já mencionada insatisfação com o Judiciário brasileiro, também a certeza da impunidade era fator motivador para a ação dos justiceiros. Assim, vê-se uma dupla relação com esse Poder, pois aquilo que era considerado incompetência da justiça tanto levava pessoas a tomarem a tarefa para si, quanto dava a esses criminosos a certeza da impunidade. Os números são contundentes em relação à impunidade: dos assassinatos de jovens ocorridos entre 1986 e 1992, somente em $36 \%$ dos casos inquéritos policiais foram abertos e desses, apenas $20 \%$ dos assassinos identificados pela polícia foram condenados.

No segundo grupo estariam o dinheiro recebido em pagamento pelos serviços prestados - que, em julho de 1991, chegava a meio salário mínimo por morte; e a forma como crianças e adolescentes pobres eram percebidos por comerciantes, que consideravam que a presença delas na frente dos seus comércios espantava clientes, consequentemente diminuindo as vendas. Além disso, aqueles jovens que trabalhavam no comércio informal eram tidos como uma forma de concorrência injusta com os estabelecimentos que pagavam impostos e aluguel (HUGGINS, 2005). A CPI também concluiu que o fator econômico era um levado em consideração por justiceiros e grupos de extermínio, pois afirma que os mesmos agiam por "torpes motivos, dinheiro ou sórdido prazer." (CPI, 1992, p. 3)

A promotora pública Tânia Maria Salles Moreira, que atuava na cidade de Duque de Caxias, afirmou haver uma outra modalidade de extermínio, que chamou de "treino diário":

A SRA. TÂNIA MARIA SALLES MOREIRA - (...) Porque o extermínio ocorre de duas formas: o extermínio à paga, que é a morte que rende e tem aquilo que, ironicamente, chamamos de treino diário. No primeiro caso, a vítima é uma pessoa cuja morte interessa a alguém e volta e meia ocorre, mas não é todo dia. O matador profissional, como qualquer profissional, precisa manter-se em atuação, à fim de que continue tendo junto à comunidade sua fama e sua tática ou técnica, como queiram chamar. (CPI, 1992, p. 30) 
Esses seriam os crimes cometidos para que o matador pudesse afirmar seu papel na comunidade em que estava inserido, para que se mantivesse a construção de sua imagem como homem perigoso e poderoso. Para a promotora pública, o simples ato de derrubar um copo de cerveja poderia ser suficiente para levar ao crime. Pode-se então cruzar os crimes de "treino diário" com aqueles cometidos por motivos torpes, visto que bastava desagradar ao matador para tornar-se sua vítima.

Huggins afirma que há uma condição mista dos agentes da violência pública no Brasil, pois esses são policiais em serviço, vigilantes que trabalham para firmas privadas de segurança e justiceiros, que atuam tanto individualmente quanto em grupo (HUGGINS, 2010). Acrescento ainda policiais fora de serviço como agentes dessa violência, pois muitas vezes esses atuavam como justiceiros ou trabalhavam para empresas de segurança, ainda que isso não fosse permitido nos termos da lei. $O$ fenômeno da privatização da segurança passa também pela criação e proliferação dessa indústria, que não raro estava envolvida em crimes de extermínio. As empresas de segurança privada estão sob a fiscalização da Polícia Federal, que requer registro tanto da empresa quanto de seus funcionários. Tal medida foi tomada para solucionar um problema de "lealdades conflitantes, que contrapunham, por vezes, os vigilantes e os funcionários e leis municipais, estaduais ou federais."(HUGGINS, 2010, p. 550)

Na prática, no entanto, era comum que funcionassem sem qualquer controle do Estado. Tânia Maria Salles Moreira denunciou três dessas empresas que funcionavam na região da Baixada Fluminense: Associação Guarda Noturna de Duque de Caxias e SOS Serviços Gerais Ltda., ambas em Duque de Caxias; e Vigilância Jeans, de São João do Meriti. Diante da denúncia, a presidência da CPI solicitou, em 18 de junho, ao Ministro da Justiça, senador Jarbas Passarinho, informações sobre o funcionamento das empresas Associação Guarda Noturna de Duque de Caxias e SOS Serviços Gerais Ltda., ambas em Duque de Caxias; e Vigilância Jeans, de São João do Meriti, todas no estado do Rio de Janeiro. Requerimentos também foram remetidos a todas as empresas para que prestassem informações em um prazo de 15 dias, para que fossem cruzadas com os dados oficiais (CPI, 1992, p. 53). Não há indício de que a documentação solicitada tenha sido remetida pelas empresas e o nome das três, bem como seus proprietários, constam no relatório final da CPI como "empresas de segurança de funcionamento clandestino e dirigidas por integrantes de grupos de extermínio.” (CPI, 1992, p. 09) 
Foi também no dia 18 de junho que um/a parlamentar encaminhou requerimento solicitando as presenças dos presidentes da Associação Comercial de Duque de Caxias e do Clube dos Diretores Lojistas do Rio de Janeiro. O primeiro, Getúlio Gonçalves, anteriormente mencionado, era suspeito de pagamento a vigilantes que deveriam agir para eliminar aqueles cuja presença era considerada prejudicial para o andamento do comércio de Duque de Caxias. (CPI, 1992, p. 36)

O depoente negou qualquer envolvimento seu ou da Associação Comercial de Duque de Caxias com ações de extermínio. No entanto, quando interpelado pela deputada federal Fátima Pelaes, admitiu saber da existência de grupos com esse caráter em seu município:

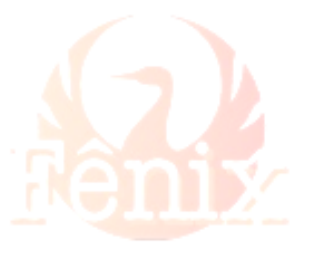

Outro ponto relevante da interpelação foi o questionamento quanto a sua relação com Pedro Bueno, conhecido como "Pedro Capeta". A primeira pergunta, feita pela deputada federal Fátima Pelaes, questionava a natureza do relacionamento entre os dois, ao que Getúlio Gonçalves respondeu que o conhecia, pois havia sido candidato a vereador pelo seu partido, o PTB, mas que sua aproximação com "Pedro Capeta" se deu por este ter prestado socorro a sua irmã - sem saber que se tratava dela - quando essa foi vítima de um atropelamento no centro da cidade. Assim, tinha um sentimento de dívida de gratidão para com ele.( CPI, 1992, p. 78)

Cinco depoentes da CPI fizeram denúncias contra "Pedro Capeta" em seus depoimentos, que fora preso em flagrante em Nova Iguaçu enquanto atuava no extermínio de uma família e tinha consigo uma arma que deveria estar acautelada na $4^{\text {a }}$ Vara Criminal (CPI, 19985, p. 25). Após essa prisão, o julgamento foi marcado com 
menos de 24 horas antecedência e o réu absolvido por 7 a 0 (CPI, 1992, p. 38). Absolvido, foi acolhido por apoiadores em uma comemoração na saída do Fórum.

Essas redes de sustentação eram compostas não só pelos membros da comunidade em que os justiceiros estavam inseridos, mas também por agentes do Poder Público. Quando de sua prisão, Pedro Bueno tinha consigo uma carteira de oficial de Justiça ad hoc. A prática de expedição de carteirinhas de oficial de Justiça ad hoc já havia sido mencionada pela promotora Tânia Maria Salles Moreira, que entendia que essas serviam para garantir porte de armas sem que houvesse a solicitação formal para a Secretaria de Segurança Pública, responsável pela emissão do mesmo. Assim, “os juízes concediam porte de arma a integrantes de grupo de extermínio que conviviam ali diariamente no Juízo. Isso, evidentemente, afastava as testemunhas do Juízo" (CPI, 1992, p.25). Apurou-se que essas carteirinhas haviam sido expedidas por Luís César Aguiar Bittencourt Silva, juiz em Duque de Caxias entre 1968 e 1981, e naquele momento atuando em Alagoas. No dia 12 de setembro, ele se apresentou para depor na CPI e explicou que aquele procedimento estava dentro da legalidade e era adotado devido ao baixo número de oficias de justiça de que dispunha.

Ainda que as práticas fossem consideradas legais, $\mathrm{o}$ fato de as carteirinhas serem renovadas ano após ano é indício de que existia já uma rede a quem Luís César Aguiar Bittencourt Silva as concedia. Além disso, o critério para a distribuição era o mesmo utilizado para a cessão de armas: era preciso uma ficha policial limpa e ser considerado um cidadão de bem pelo juiz, o que, evidente, tornava a escolha bastante subjetiva. Importante mencionar que o filho de Pedro Bueno, João Carlos Bueno, trabalhou como motorista de Luís César Aguiar Bittencourt Silva por um ano, quando esse foi presidente do Tribunal de Justiça. Afirmou, no entanto, que nunca concedeu carteirinha de oficial ad hoc para ele, o que era de responsabilidade de outro juiz. Quando questionado sobre Pedro Bueno, o magistrado pareceu convencido da inocência desse, visto que havia sido julgado e absolvido, inclusive com pedido de absolvição do Ministério Público. Diferente do magistrado, a CPI entendeu que "Pedro Capeta" era, sim, membro de grupo de extermínio na Baixada Fluminense, conforme consta no relatório final.

A segunda pessoa convocada a depor devido a acusações de apoio ao extermínio de crianças e adolescentes pobres foi o presidente do Clube de Diretores Lojistas e vice-presidente da Associação Comercial do Rio de Janeiro, Sílvio Siqueira 
da Cunha, que compareceu à sessão da CPI do dia 22 de agosto de 1991. A primeira referência a ele foi feita por Volmer do Nascimento, líder do MNMMR, que citou uma entrevista dada pelo empresário em que disse que "todo pivete que se mata é um bem que se faz à sociedade" (CPI, 1992, p.38). Em depoimento, o Sílvio Cunha alegou que foi a deturpação de suas palavras que o levou até ali. E explicou o caso: o Ministro da Saúde, Alceni Guerra, em visita à Associação Comercial do Rio de Janeiro, no dia 10 de janeiro daquele ano, havia dito que os empresários do Rio de Janeiro financiavam o extermínio de crianças e menores. Como representante de classe, saiu em defesa do empresariado, dando, em programa de rádio, uma declaração em resposta as acusações do Ministro. (CPI, 1992, p. 109)

Após a reprodução, no Plenário, da gravação do mencionado programa de rádio, a interpelação seguiu com tensão e, além da acusação de apologia ao crime levantada pelo deputado Jurandyr Paixão - também uma questão em torno do falso testemunho foi colocada, visto que o depoente havia negado o teor de sua fala antes de a fita ser ouvida pelas pessoas que ali estavam. Insistindo que houvera uma má interpretação do que dissera, Sílvio Siqueira da Cunha alegou que se referia a "pivetes" e não a crianças ou menores. Pivete, para ele, era aquele adolescente que "já tem de uma determinada idade em diante, já agridem, já assaltam livremente" (CPI, 1992, p. 111). Questionado sobre que idade seria essa, respondeu 16 anos - não sem oscilar entre essa e 14 anos -, porque com 16 anos já são vistos de modo diferente perante a lei - afinal, podem votar. E complementou afirmando que em locais empobrecidos, como favelas, havia o costume de não registrar a criança quando nasce, e sim quando já tem alguns anos de vida, o que faria com que muitos menores de idade, na verdade, não o fossem. (CPI, 1992, p. 111)

Para reparar aquilo que considerava um problema de interpretação da sua colocação, o depoente já havia mandado nota de retratação para a imprensa no dia 13 de janeiro, mas só o jornal $O$ Globo a publicara. Foi solicitado pelo deputado Jurandyr Paixão que, através das associações de classe de que era membro, fosse feita a publicação paga da nota em questão, o que, respondeu, já havia sido feito, em 26 do mesmo mês, em jornais do Rio de Janeiro. A deputada Célia Mendes acrescentou que a publicação deveria ser feita também na grande mídia, visto que o caso havia ganhado repercussão nacional. Como providências quanto ao teor da declaração já estavam sendo tomadas pelo Ministério Público, a CPI decidiu por encaminhar ao mesmo, através do 
Dr. Álvaro Augusto Ribeiro Costa, Subprocurador-Geral da República, presente naquela sessão, a fita apresentada pela deputada Benedita da Silva e as notas taquigráficas do depoimento e da inquirição para que este deliberasse se havia ocorrido crime de falso testemunho. Por fim, o depoente fez um apelo à Comissão para que pudesse ir "tranqüilo para a minha casa, sem ter mais o dissabor de ter momentos que me façam relembrar aquilo de que eu me manifestei arrependido" (CPI, 1992, p. 118). Não há qualquer menção a Sílvio Siqueira da Cunha no Relatório Final da CPI.

Tampouco consta no citado relatório o nome de Clidenor Anselmo Brilhante, de apelido Esquerdinha, que depôs na CPI no dia 05 de setembro de 1991. Clidenor Anselmo Brilhante foi o último dos três convocados a depor na CPI suspeitos de ligação com empresas de segurança que atuavam como grupos de extermínio. Sua convocação foi feita a partir da solicitação dos deputados Eduardo Braga e Célio de Castro, após denúncia feita por Gilberto Dimenstein, jornalista da Folha de S. Paulo.

Quando do início da sessão que ouviria o senhor Clidenor Brilhante, foi solicitado que o deputado Célio de Castro explicasse ao depoente o porquê de sua convocação. O deputado federal afirmou então que o mesmo se encontrava ali como depoente e não como acusado de algum crime. Todavia constavam denúncias de que era dono de várias firmas de segurança na região de São Bernardo do Campo, e que essas firmas estariam envolvidas em maus-tratos e extermínio de crianças (CPI, 1992, p. 130). Em sua fala inicial, Clidenor Ancelmo Brilhante afirma estar processando Gilberto Dimenstein pelas acusações que este fez em seu livro ${ }^{9}$ e que nunca foi entrevistado pelo jornalista. Para ele, “a realidade é uma só: o sr. Gilberto Dimenstein está querendo ganhar dinheiro e se promover nas costas desses pobres infelizes que vivem na rua". (CPI, 1992, p. 130)

O depoente negou que tivesse atuação como justiceiro em sua região, mas chamou atenção para uma questão: era preciso diferenciar justiceiros de pistoleiros de aluguel. Os últimos eram, segundo ele, aqueles que agiam mediante pagamento para dar fim a vida de um desafeto do contratante do serviço. Já o justiceiro era aquele que:

9 O livro em questão é o seguinte: DIMENSTEIN, 1990. Sobre Clidenor Ancelmo Brilhante, consta: “Eu não considero ser humano quem estupra, mata a sangue frio. Para mim, isso não é gente, é piolho. E piolho a gente esmaga - disse à Folha de S. Paulo, em março de 1988, Clidenor Ancelmo Brilhante, conhecido como 'Esquerdinha', apontado como principal ‘justiceiro' de São Bernardo. Ele chegou a receber o título de 'Cidadão de São Bernardo' oferecido pela Câmara Municipal por seu trabalho de 'limpeza' da cidade. É um 'justiceiro sofisticado', dono de uma empresa de segurança que batizou como Rota. Antes de ter essa empresa, 'Esquerdinha' trabalhava diretamente para a polícia.” (p. 31) 
Disponível em: www.revistafenix.pro.br

O SR. CLIDENOR ANCELMO BRILHANTE - (...) Foi assaltado, procurou a polícia duas ou três vezes e, como ninguém tomou atitude, toma a atitude dele. (...) Aí ele passa a ser respeitado no bairro. A população passa a considerá-lo herói. O próprio morador paga. Às vezes, eles perde (sic) o emprego ou larga, porque dá o cano, e passa a viver do pagamento dos próprios moradores. (CPI, 1992, p. 134)

Se por serem vistos como heróis ou por serem temidos, receber pagamento de moradores da comunidade em que atuavam era uma característica dos justiceiros. A deputada Rita Camata o questionou acerca do pagamento e de eventuais consequências do não-pagamento:

O SR. CLIDENOR ANCELMO BRILHANTE - O bairro tem mais ou menos de doze a quinze mil casas. Se todas essas famílias pagam, eu não tenho certeza. Se eu soubesse que era isso, poderia até ter trazido as fichas para vocês verem como é. Se pagam, umas quinhentas casas. Quem paga é amigo, quem não paga é amigo, a mesma coisa. Não tem nada a ver uma coisa com a outra. Há cidadão que paga e há cidadão que no outro mês não consegue pagar. Olha, atrasou, fiz greve e não recebi! Não tem nada a ver. (CPI, 1992, p. 141-142)

A ideia de que não havia consequências para eventuais não pagadores é questionável, visto que esses homens se impunham nas comunidades pelo uso da força e da violência e, consequentemente, da construção do medo. Também havia, contudo, apoio popular daqueles que se sentiam protegidos ou eram beneficiados pela atuação desses personagens em locais em que a ação do poder público era pouco eficiente.

Nesse sentido, é emblemático o caso do próprio Esquerdinha: no dia da audiência de conciliação do caso em que processava Gilberto Dimenstein, que fora anunciada na TV, mais de 500 crianças foram para a frente do fórum com "pais de família" a fim de apoiá-lo, levando cartazes e faixas que pediam pela prisão de traficantes e não a sua (CPI, 1992, p.141). Percebe-se, então, como a figura do justiceiro era forjada de forma complexa, indo além da simples perversidade dos perpetradores de tamanha violência contra crianças e jovens a quem cabia o vocativo "menor". 


\section{REFERÊNCIAS BIBLIOGRÁFICAS}

AGAMBEN, Giorgio. Homo sacer: o poder soberano e a vida nua I. Belo Horizonte: Editora UFMG, 2002.

AREND, Silvia Maria Fávero. Histórias do abandono: infância e justiça no Brasil (década de 1930). Florianópolis: Editora Mulheres, 2011.

BARROS, Ricardo Paes de; HENRIQUES, Ricardo; MENDONÇA, Rosane. Desigualdade e pobreza no Brasil: retrato de uma estabilidade inaceitável. Revista Brasileira de Ciências Sociais, v. 15, n. 42, p. 123-142, fev. 2000.

CALDEIRA, Teresa Pires do Rio; HOLSTON, James. Democracy and violence in Brazil. Comparative Studies in Society and History, Cambridge, v. 41, n. 4, p. 691729, oct. 1999.

CARDIA, Nancy. Direitos humanos: ausência de cidadania e exclusão moral. São Paulo: Comissão de Justiça e Paz, 1995.

CASTRO, Myrian Mesquita Pugliese de. Assassinatos de crianças e adolescentes no Estado de São Paulo. Revista Crítica de Ciências Sociais, Coimbra, n. 36, p. 81-102, fev. 1993.

CUNNINGHAM, Hugh. Histories of Childhood. The American Historical Review, Vol. 103, No 4, 1998, p. 1195-1208.

DIMENSTEIN, Gilberto. A guerra dos meninos: assassinato de menores no Brasil. São Paulo: Editora Brasiliense, 1990.

FRONTANA, Isabel C. R. da Cunha. Crianças e adolescentes nas ruas de São Paulo. São Paulo: Edições Loyola, 1999.

HUGGINS, Martha Knisely. Exclusion, Civic Invisibility and Marginality. In: DENNIS, Rutledge (Org.). Marginality, power, and social sctructure: issues in race, class, and gender analysis. Kidlington: Elsevier, 2005. p. 71-92.

HUGGINS, Marta.Violência urbana e privatização do policiamento no Brasil: uma mistura invisível. Caderno CRH, Salvador, v. 23, n. 60, p. 541-558, set./dez. 2010.

MALLMANN, Maria Izabel. Os ganhos da década perdida: democracia e diplomacia regional na América Latina. Porto Alegre: EDIPUCRS, 2008.

PERES, Maria Fernanda Tourinho; CARDIA, Nancy; SANTOS, Patrícia Carla dos Santos. Homicídios de crianças e jovens no Brasil: 1980-2002. São Paulo: Núcleo de Estudos da Violência - Universidade de São Paulo, 2006.

PINHEIRO, Paulo Sérgio. Democratic consolidation and human rights in Brazil. Working Paper \#256. Kellogg Institute, p. 1-45, 1998.

ROCHA, Sonia. Pobreza e indigência no Brasil: algumas evidências empíricas com base na PNAD 2004. Nova Economia, Belo Horizonte, v. 16, n. 2, p. 265-299, mai./ago. 2006.

SINGER, Paul. Evolução da economia e vinculação internacional. In: SACHS, Ignacy; WILHEIM, Jorge; PINHEIRO, Paulo Sérgio (Orgs.). Brasil: um século de transformações. São Paulo: Companhia das Letras, 2001, p. 78-131.

\section{OUTRAS FONTES}

DIMENSTEIN, Gilberto. Senador quer CPI para crimes contra menores. Folha de $\mathbf{S}$. Paulo, 29 set. 1989. Caderno Cidades.

CPI Destinada a Investigar o Extermínio de Crianças e Adolescentes no Brasil, 1992. 
Diário da Câmara dos Deputados, Brasília, ano 45, n. 33, 25 de abril de 1990, p. 3393. Diário da Câmara dos Deputados, Brasília, ano 46, n. 6, 22 de fevereiro de 1991, p. 519 520.

Diário da Câmara dos Deputados, Brasília, ano 45, n. 43, 10 de maio de 1990, p. 4568. Diário da Câmara dos Deputados, Brasília, ano 46, n. 10, 05 de março de 1991, p. 881. ESQUADRÃO da Morte mata um menor a cada 2 dias no país. Folha de S. Paulo. São Paulo. 26 set. 1989. Capa. 